\title{
Striatal Cholinergic Cell Ablation Attenuates L-DOPA Induced Dyskinesia in Parkinsonian Mice
}

\author{
Lisa Won, ${ }^{1 \star}$ Yunmin Ding, ${ }^{1,2 \star}$ Pardeep Singh, ${ }^{2}$ and Un Jung Kang ${ }^{1,2}$ \\ ${ }^{1}$ Department of Neurology, The University of Chicago, Chicago, Illinois 60637, and ${ }^{2}$ Department of Neurology, Columbia University, New York, New York \\ 10032
}

3,4-Dihydroxyphenyl-L-alanine (L-DOPA)-induced dyskinesia (LID) is a debilitating side effect of long-term dopamine replacement therapy in Parkinson's Disease. At present, there are few therapeutic options for treatment of LID and mechanisms contributing to the development and maintenance of these drug-induced motor complications are not well understood. We have previously shown that pharmacological reduction of cholinergic tone attenuates the expression of LID in parkinsonian mice with established dyskinesia after chronic L-DOPA treatment. The present study was undertaken to provide anatomically specific evidence for the role of striatal cholinergic interneurons by ablating them before initiation of L-DOPA treatment and determining whether it decreases LID. We used a novel approach to ablate striatal cholinergic interneurons (ChIs) via Cre-dependent viral expression of the diphtheria toxin A subunit (DT-A) in hemiparkinsonian transgenic mice expressing Cre recombinase under control of the choline acetyltransferase promoter. We show that Cre recombinase-mediated DT-A ablation selectively eliminated ChIs when injected into striatum. The depletion of ChIs markedly attenuated LID without compromising the therapeutic efficacy of L-DOPA. These results provide evidence that ChIs play a key and selective role in LID and that strategies to reduce striatal cholinergic tone may represent a promising approach to decreasing L-DOPAinduced motor complications in Parkinson's disease.

Key words: behavior; cholinergic; diphtheria toxin; dyskinesia; Parkinson's disease; striatum

\section{Introduction}

Parkinson's disease (PD) is a neurodegenerative disorder with prominent motor symptomatology including akinesia, rigidity, tremor, as well as instability of gait and posture. The motor deficits arise from striatal dopamine (DA) depletion resulting from the degeneration of nigrostriatal dopaminergic neurons. Pharmacotherapy with the dopamine precursor, 3,4-dihydroxyphenyl-L-alanine (L-DOPA), dramatically alleviates the motor symptoms (Fahn et al., 2004). However, motor response complications such as abnormal involuntary movements (AIMS) or dyskinesias occur within a few years of treatment (Ahlskog and Muenter, 2001). The exact mechanisms underlying the development and expression of L-DOPA-induced dyskinesias (LID) are unclear, but aberrant striatal plasticity ensues from DA denerva-

\footnotetext{
Received July 7, 2013; revised Nov. 25, 2013; accepted Dec. 19, 2013.

Author contributions: L.W., Y.D., and U.J.K. designed research; L.W., Y.D., P.S., and U.J.K. performed research; L.W. and Y.D. contributed unpublished reagents/analytic tools; L.W., Y.D., P.S., and U.J.K. analyzed data; L.W., Y.D., and U.J.K. wrote the paper.

This research was funded by NIH Grant R01 NS 064439, the Michael J. Fox Foundation for Parkinson's Research, and Parkinson's Disease Foundation (U.J.K.). We thank Dr. Rong Xia for preparation of the DT-A vector construct and Dr. Sungik Lee for assisting with behavioral analysis. We also thank Dr. Vytautas P. Bindokas (University of Chicago BSD Microscopy Core Facilities, Chicago, IL) and Dr. Mark Sonders (Columbia University, Confocal core facility of division of movement disorder) for assistance with confocal microscopy and Dr. Gopal Thinakaran (University of (hicago) for providing Odyssey Image System.

The authors declare no competing financial interests.

*L.W. and Y.D. contributed equally to this work.

Correspondence should be addressed to Dr. Un Jung Kang, Department of Neurology, Columbia University, BB302, 630 West $168^{\text {th }}$ Street, New York, NY 10032. E-mail: ujk2101@columbia.edu.

DOI:10.1523/JNEUROSCI.2888-13.2014

Copyright $\odot 2014$ the authors $\quad 0270-6474 / 14 / 343090-05 \$ 15.00 / 0$
}

tion in combination with DA replacement therapy (Picconi et al., 2003). DA depletion and chronic L-DOPA create an imbalance in striatal neurotransmitter systems and glutamatergic, serotonergic, and peptidergic system changes have been noted in LID (Huot et al., 2013). Notably, the opposing balance between cholinergic and dopaminergic system has been noted for some time (DeBoer et al., 1993; Jackson et al., 1993; Maurice et al., 2004).

We have recently reported that elevated cholinergic signaling may contribute to motor complications arising from long-term L-DOPA therapy in PD. Repeated L-DOPA administration in parkinsonian mice resulted in LID associated with enhanced response to dopamine in terms of ChI neuron excitability and extracellular signal-regulated kinase (ERK) activation in cholinergic interneurons (ChIs) of denervated striatum (Ding et al., 2011). Moreover, the expression of LID was partially attenuated by systemic administration of dicyclomine, a muscarinic receptor antagonist, as well as treatment with an inhibitor of ERK phosphorylation. Recently the role of nicotinic receptors in LID has been also recognized (Bordia et al., 2010; Quik et al., 2013).

To examine the role of ChIs in LID and therapeutic effect of L-DOPA further, we used a novel experimental technique that allows anatomic specificity of targeting only the striatal ChI, which has not been possible with pharmacological studies. This approach involves selective toxin ablation of striatal ChIs via Credependent viral expression of the diphtheria toxin A subunit (DT-A) in transgenic mice expressing Cre recombinase under control of the choline acetyltransferase (ChAT-Cre mice) promoter. DT-A induces cell death by catalyzing the inactivation of 
elongation factor 2 and terminating protein synthesis, and has been used successfully for selective CNS cell ablation (Traka et al., 2010). The present results indicate that elimination of striatal ChIs in the lesioned striatum of hemiparkinsonian mice attenuates the development of LID without affecting the beneficial antiparkinsonian action of L-DOPA.

\section{Materials and Methods}

Animals. Bac transgenic mice expressing Cre recombinase under control of the choline acetyltransferase promoter (stock transgenic: Chat-Cre GM24Gsat/Mmcd) were obtained from the Mutant Mouse Regional Resource Centers (University of California, Davis) and were maintained on a C57BL/6 background. All procedures were approved by the Institutional Animal Care and Use Committee of the University of Chicago and animals were maintained in a pathogen-free environment with ad libitum access to food and tap water.

6-OHDA lesion and AAV injection. Unilateral 6-hydroxydopamine (6OHDA) lesion (Lundblad et al., 2004; Ding et al., 2011) was performed in 9- to 12-month-old ChAT-Cre male and female animals. Mice received unilateral lesion of the left medial forebrain bundle by intracranial infusion of $4.5 \mu \mathrm{g}$ of 6-OHDA free base in $1.5 \mu \mathrm{l}$ of $0.05 \%$ ascorbic in $0.9 \%$ saline into the following coordinates: anterior/posterior $(-1.3 \mathrm{~mm})$, medial/lateral $(+1.1 \mathrm{~mm})$, and ventral to skull surface $(-5.4 \mathrm{~mm})$. Desipramine $(25 \mathrm{mg} / \mathrm{kg}$, Sigma-Aldrich) was given $30 \mathrm{~min}$ prior the infusion of 6-OHDA to protect norepinephrine neurons. Following surgery, mice received 3-4 weeks of intensive postoperative care consisting of twice daily, $1 \mathrm{ml}$ injections (i.p.) of $5 \%$ dextrose in $0.9 \%$ saline and highly palatable, bacon softies (Bio-Serv) as supplementation to the normal mouse chow diet. During the postoperative period, three mice died after unilateral 6-OHDA lesion and the remaining 22 mice with confirmed stepping deficits by $>50 \%$ were divided randomly into two groups to receive either intrastriatal adeno-associated virus (AAV)-DT-A $(n=10)$ or AAV-enhanced yellow fluorescent protein (EYFP) $(n=12)$ injection.

Full length of cDNA coding for DT-A (Traka et al., 2010) (provided by Dr Brian Popko, The University of Chicago) was inserted into vector pAAV-Efla-DIO-hChR2(H134R)-mCherry-WPRE-pA (Witten et al., 2010; provided by Dr Karl Deisseroth, Stanford University) by replacing hChR2(H134R) with the DT-A coding sequence. AAV5 with a loxP DT-A insert (AAV5-Flex-DTA-mCherry-WPRE, $2 \times 10 \mathrm{e} 12$ virus particles/ml titer, was injected into two striatal sites; $2 \mu \mathrm{l} /$ site, coordinates: Site $1, \mathrm{AP}+1.1 \mathrm{~mm}, \mathrm{ML}+1.5 \mathrm{~mm}$, ventral to the skull surface $-3.1 \mathrm{~mm}$; Site 2, $\mathrm{AP}+0.5 \mathrm{~mm}, \mathrm{ML}+1.9 \mathrm{~mm}$, ventral to the skull surface $-3.1 \mathrm{~mm}$ ) on the lesioned side of ChAT-Cre mice. A control group received similar striatal injections of AAV5-double-floxed inverted orientation-eYFP (AAV5/EF1a-DIO-EYFP, $3 \times 10 \mathrm{e} 12$ virus particles/ml). AAV5 vectors were produced by the University of North Carolina Gene Therapy Center.

Drug treatment and behavioral tests. The ablation of ChIs was verified by immunohistochemistry 4 weeks following injection of AAV-DT-A (data not shown). Therefore, L-DOPA methyl ester administration was initiated 4 weeks following injection of AAV-DT-A or AAV-eYFP. L-DOPA ( $1 \mathrm{mg} / \mathrm{kg}$ in $0.9 \%$ saline) and $12.5 \mathrm{mg} / \mathrm{kg}$ benserazide, the peripheral L-DOPA decarboxylase inhibitor (Sigma-Aldrich) were administered intraperitoneally in $0.1 \mathrm{ml}$ volume $/ 20 \mathrm{~g}$ body weight. Mice were injected once per day with the exception of days when behavioral testing was conducted.

Behavioral testing for dyskinesia following a challenge dose of $3 \mathrm{mg} / \mathrm{kg}$ L-DOPA was conducted on days $1,8,22$, and 36 of repeated drug treatment. Mouse behavior was video recorded for 3 min every 20 min during a $2 \mathrm{~h}$ period following L-DOPA challenge. Limb and axial dyskinesias were scored separately for the middle 2 min period of the video recording by an observer blinded to treatment conditions with following modification of a previously described rating scale (Lundblad et al., 2004). Each dyskinesia subtype was scored from 0 to 4 in terms of severity as well as amplitude such that each mouse could reach a theoretical maximum score of 48 for each of the four test sessions during the repeated L-DOPA treatment period (Ding et al., 2011). Stepping tests to assess akinesia were performed by a modification of previously published procedure (Chang et al., 1999), placing both forelimbs on a treadmill moving forward 4 weeks postlesion before AAV injection and again, 5-8 weeks following repeated L-DOPA treatment. Forepaw steps were video recorded of five nonconsecutive cycles of treadmill before and $60 \mathrm{~min}$ after injection of 3 $\mathrm{mg} / \mathrm{kg}$ L-DOPA. The number of left and right paw steps was counted for each of the five cycles and averaged. At the end of the experiment, mice receiving repeated L-DOPA were administered a final injection of L-DOPA $(3 \mathrm{mg} / \mathrm{kg})$ and then perfused $20 \mathrm{~min}$ later for immunocytochemical analyses.

Immunohistochemistry. At the end of repeated treatment with L-DOPA, animals were perfused, fixed, cryopreserved as described before (Ding et al., 2007). Coronal serial brain sections were made at $20 \mu \mathrm{m}$ with a sliding microtome (Leica Instruments) and immunostaining was performed as described previously (Ding et al., 2007). Primary antibodies used were goat anti-DARPP-32 (1:2000, BD Bioscience), rabbit antiphospho-ERK (pERK, 1:200, Cell Signaling Technology), rabbit antiNeuN (1:4000, Millipore), rabbit anti-GFP (1:20,000, this antibody also recognizes EYFP, Invitrogen), goat anti-ChAT (1:1000, BD Bioscience), rabbit anti-TH (1:500, Pel-Freez Biologicals). Alexa Fluor 488 and Alexa Fluor 647-conjugated secondary antibodies (1:500, Invitrogen) were diluted in either $3 \%$ BSA (for pERK) or 5\% appropriate normal serum (for nonphospho-protein detection) for fluorescent microscopy. IRDye@ $800 \mathrm{CW}$-conjugated secondary antibody (1:1000, LI-COR Biosciences) was applied for TH immunostaining to evaluate the extent of dopaminergic denervation. One set of striatal sections was used for bright-field microscopy of ChAT and Nissl staining. Sections were incubated in ChAT antibody, then with biotinylated horse anti-Goat IgG followed by incubation in ABC (Vector Laboratories) and visualized with $0.05 \% 3,3^{\prime}$ diaminobenzidine (DAB) solution.

Image analysis. All image analysis was performed with ImageJ software. Numbers of ChAT-immunopositive neurons were counted in four sequential fluorescent labeled sections of the striatum between bregma 0.14-1.18 mm (Paxinos and Franklin, 1997) spaced at $220 \mu \mathrm{m}$ apart on montage images of the entire striatal cross section taken at $20 \times$ magnification with Marianas Yokogawa type spinning disk inverted confocal fluorescence microscope (Intelligent Imaging Innovations). Striatal pERK, NeuN and DARPP-32 neurons were quantitated from random selection of 1-3 images (image size: $775 \mu \mathrm{m} \times 775 \mu \mathrm{m}$ ) per section covering the lateral striatum, a region that mediates LID (Andersson et al., 1999; Andersson et al., 2001) in four sequential coronal sections. The images were taken with $20 \times$ objective lens by Leica SP 5 confocal microscope (model DM $6000 \mathrm{CFS}$ ). For the analysis of images with combined ChAT immunostaining by DAB and Nissl staining, 2-3 images (image size: $900 \mu \mathrm{m} \times 900 \mu \mathrm{m}$ ) were taken from the lateral striatum of 4 coronal sections at $20 \times$ using bright field microscopy. Behavioral and image analyses were done excluding mice that had died during L-DOPA treatment or had nonspecific damage from viral injection. The extent of striatal dopamine denervation produced by 6-OHDA was evaluated from TH immunostained coronal sections of striatum using the infrared Odyssey Image Analysis system (LI-COR Biosciences). Neurotoxin lesion resulted in a similar degree of reduction in striatal TH intensity (ratio of lesioned to intact striatum) between AAV-DTA $(93.2 \pm 0.5 \%$ reduction, $n=6)$ versus AAV-EYFP injected mice $(91.2 \pm 0.9 \%$ reduction, $n=11)$.

Statistics. The statistical programs, Sigma Stat version 2.0.3 and SPSS version 21 were used for data analysis. The data are represented either as the mean \pm SEM (stepping and cell quantification) or median (severity of dyskinesia) as reported previously (Winkler et al., 2002; Malmlöf et al., 2010). For all dyskinesia data, Friedmans test was first used to examine the statistical significance among medians at different time points between groups. If overall statistical significance was reached by Friedmans test $(p<0.05)$, Wilcoxon post hoc test with Bonferroni adjustment was applied for individual comparison within or between groups.

\section{Results}

Intrastriatal administration of AAV-DT-A results in selective depletion of ChIs

To ablate ChIs, we used Cre-dependent viral expression of DT-A in the lesioned striatum of transgenic mice expressing Cre recombinase 
A

B

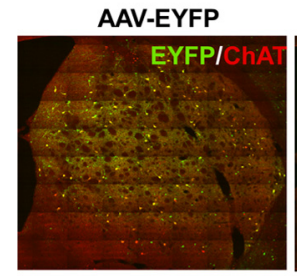

AAV-DT-A-mCherry

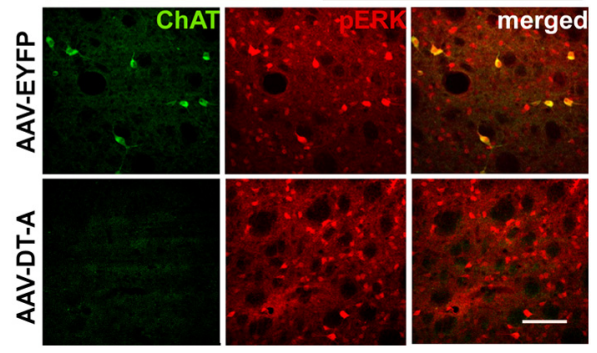

Figure 1. Elimination of cholinergic interneurons in lesioned striatum of ChAT-Cre mice. $A$, Abundant coexpression of EYFP immunolabeling (green) in striatal ChAT-positive (red) neurons of mice injected with AAV-EYFP, while the majority of ChAT neurons are ablated following injection of AAV-DT-A-mCherry (referred to in the text as AAV-DT-A). B, Repeated treatment of lesioned mice with L-DOPA results in ERK activation (pERK, red) mainly in ChAT-positive cells (green) of AAV-EYFP-injected mice, but this is not observed with AAV-DT-A-mediated cell ablation. Scale bar, $100 \mu \mathrm{m}$.

under control of the ChAT promoter. Immunohistochemistry of EYFP/ChAT expression demonstrated that stereotactic injection of AAV-EYFP efficiently transduced ChIs and covered a large extent of the lesioned striatum (Fig. 1A). The expression of the reporter gene, EYFP, was specific to ChAT-labeled cells. The elimination of striatal ChIs was verified 1 month postinjection of AAV-DT-A (data not shown) and 1-3 months afterward when the behavioral testing was completed (Fig. 1A). Conditional DT-A ablation spanned the rostral to caudal extent of the lesioned striatum and resulted in a significant $93 \%$ reduction $(p<0.001, t$ test $)$ in the number of neurons expressing ChAT in AAV-DTA-injected mice (23.0 $\pm 15.0, n=6)$ relative to AAV-EYFP controls (317.9 \pm $17.6, n=11)$. As we previously reported, repeated L-DOPA treatment results in ERK activation (phosphorylated ERK) in striatal ChIs in lesioned striatum of mice injected with AAV-EYFP, but not in animals where ChIs were ablated by AAV-DT-A (Fig. 1B). DT-A-mediated striatal cell depletion was selective for ChIs, as there was comparable immunostaining for the neuronal nuclear marker NeuN (Fig. 2A; Table 1) and the medium spiny neuron protein DARPP-32 (dopamine- and cAMP-regulated phosphoprotein Mr $32 \mathrm{kDa}$; Fig. 2B; Table 1), in lesioned striatum between AAV-DT-A- and AAV-EYFP-injected animals. Similarly, as we previously reported (Ding et al., 2011), L-DOPA still induced some ERK phosphorylation in other cell types in the denervated striatum in a similar manner in both groups (Fig. $1 A, B$; Table 1). The number of striatal large Nissl stained neurons was decreased dramatically in AAV-DT-A group compared with in AAV-EYFP group (Table 1). The reduction was mostly in ChAT-positive cells without much difference in small number of ChAT-negative large neurons, suggesting that the striatal cholinergic interneurons had been mostly eliminated, rather than simply losing expression of phenotypic markers.

ChI ablation attenuates development of L-DOPA induced AIMs but does not interfere with drug improvement of forelimb akinesia

L-DOPA induced dyskinetic behaviors were monitored over the 5 -week-period of repeated drug treatment in lesioned ChAT-Cre
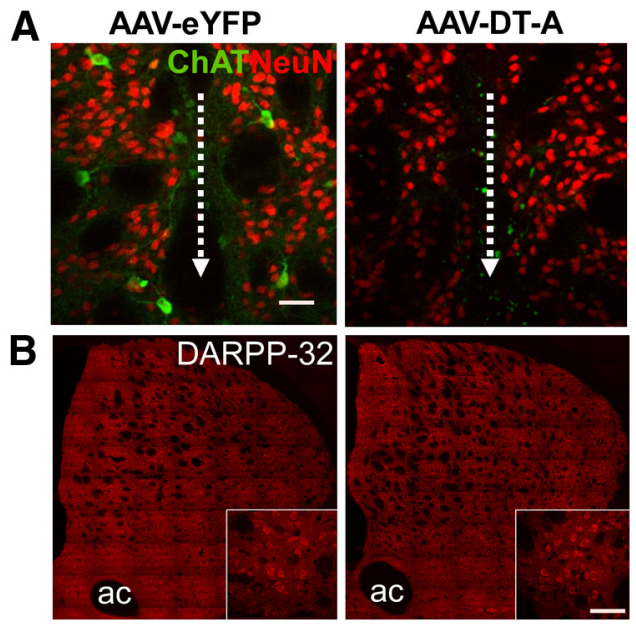

Figure 2. DT-A selectively ablates cholinergic neurons in lesioned striatum of ChAT-Cre mice. $\boldsymbol{A}$, Despite elimination of ChAT immunolabeling (green), expression of the general neuronal marker, NeuN (red), is similar in lesioned striatum of mice injected with AAV-DT-A compared with AAV-EYFP. The dotted white line and arrow indicate the injection needle track. $\boldsymbol{B}$, Immunolabeling for DARPP-32 (dopamine- and CAMP-regulated phosphoprotein Mr $32 \mathrm{kDa}$ ), a marker of striatal medium spiny neurons, is also unaffected by AAV-DT-A. ac, Anterior commissure. Scale bar, $40 \mu \mathrm{m}$.

Table 1. Quantitation of neuronal cell numbers in the denervated striatum

\begin{tabular}{llll}
\hline & AAV-EYFP & \multicolumn{1}{l}{ AAV-DT-A } & \\
\hline ChAT $^{a}$ & $317.91 \pm 17.57$ & $23 \pm 15.05$ & $p<0.05$ \\
pERK $^{b}$ & $173.98 \pm 17.703$ & $223.72 \pm 29.295$ & NS \\
NeuN $^{b}$ & $953.86 \pm 27.22$ & $953.82 \pm 27.92$ & NS \\
DARPP-32 $^{b}$ & $492.41 \pm 7.43$ & $474.54 \pm 27.06$ & NS \\
Large Nissl-stained neurons $^{c}$ & & & \\
$\quad$ ChAT+ & $13.14 \pm 0.69$ & $2.62 \pm 1.31$ & $p<0.05$ \\
$\quad$ ChAT - & $0.30 \pm 0.12$ & $0.28 \pm 0.20$ & NS \\
\hline
\end{tabular}

Data were presented as mean $\pm \mathrm{SEM}$; $t$ test was applied in the statistical analysis.

${ }^{a}$ Total fluorescent ChAT-immunopositive neurons in the entire cross-section of the striatum in four coronal montage images.

${ }^{b}$ Average number of positive staining per image (image size, $0.601 \mathrm{~mm}^{2}$ ).

'Average number of cells analyzed per image (image size, $0.81 \mathrm{~mm}^{2}$ ) in bright-field microscope.

mice (Fig. 3). Axial and limb abnormal involuntary movements (AIMs) were present upon the first administration of L-DOPA in mice injected with AAV-EYFP and remained relatively stable during the 5 weeks of L-DOPA administration (Fig. $3 A, B$ ) in this severe lesion model of PD. As LID is influenced by the severity of the lesion (Putterman et al., 2007), severe MFB lesions in our experimental group allow maximal level of LID to express without any further increase with chronic L-DOPA treatment as noted by others (Lundblad et al., 2004; Darmopil et al., 2009; Malmlöf et al., 2010). ChAT-Cre mice injected with AAV-DT-A 1 month before initiation of treatment exhibited limb and axial dyskinesias significantly lower in magnitude compared with AAV-EYFP animals throughout the course (Fig. $3 A, B$ ). The time course after a single L-DOPA dose at week 5 demonstrates a typical dramatic reduction in magnitude and duration of LID in AAV-DT-A injected mice compared with mice AAV-EYFP (Fig. 3C,D).

To evaluate cholinergic neuron involvement in lesioninduced akinesia and L-DOPA-mediated improvement of motor function, AAV-DT-A and AAV-EYFP injected mice were tested for motor performance using the forelimb adjusted stepping test (Fig. 3E,F). Unilateral lesion of the left medial forebrain bundle resulted in a significant stepping impairment of the contralateral, right forepaw in ChAT-Cre mice before virus injection. Neither 

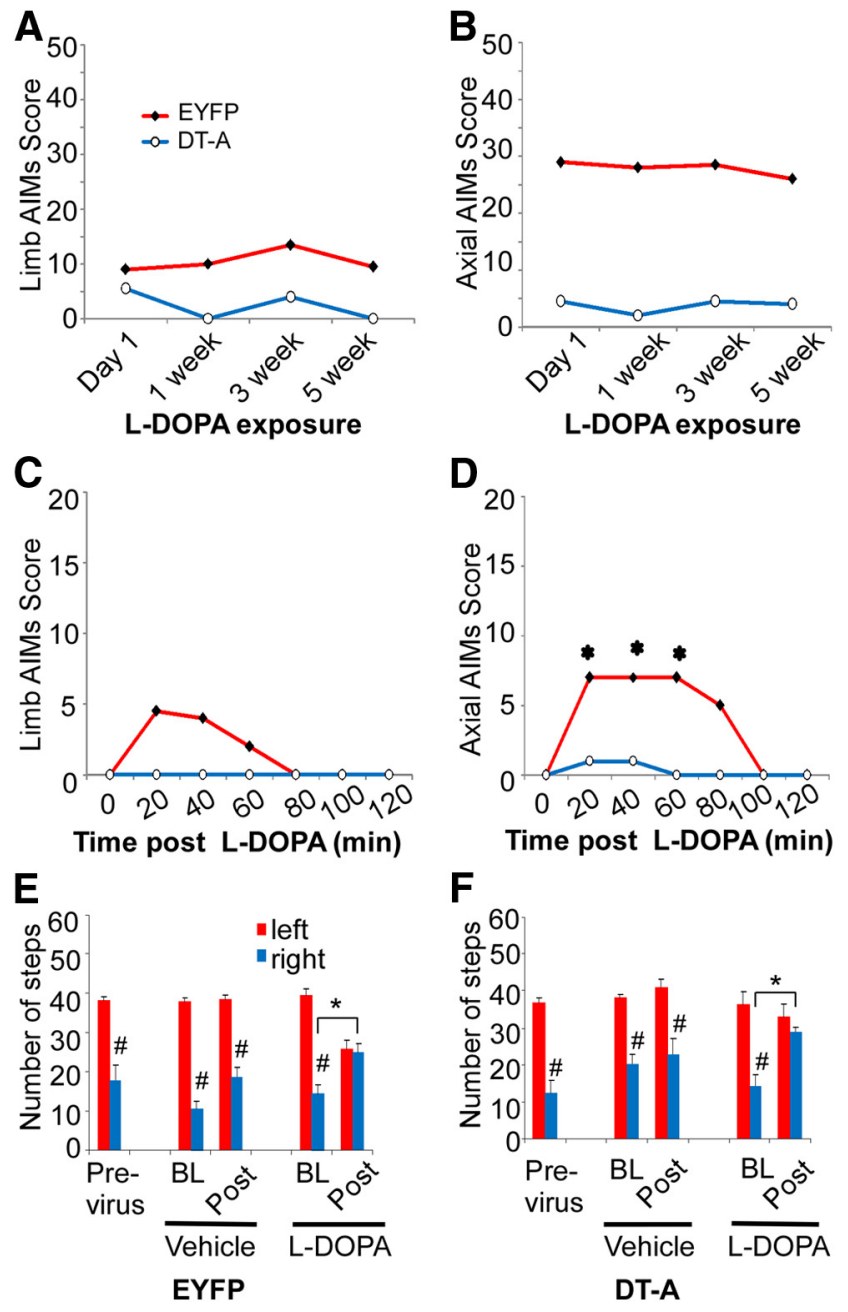

$\mathbf{F}$

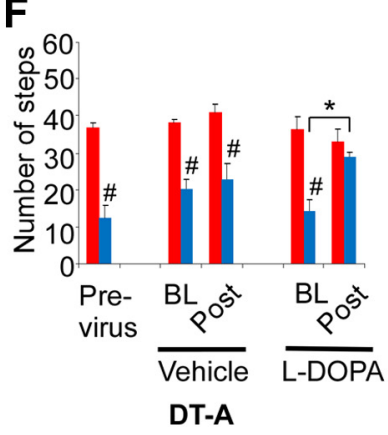

Figure 3. Effect of striatal cholinergic neuron ablation of L-DOPA-induced behaviors. Hemiparkinsonian ChAT-Cre mice injected with AAV-EYFP or AAV-DT-A into lesioned striatum were treated repeatedly with L-DOPA to induce AIMS. Mice were challenged with $3 \mathrm{mg} / \mathrm{kg}$ L-DOPA at the indicated time points and total $\operatorname{limb}(\boldsymbol{A})$ and axial $(\boldsymbol{B})$ AIM scores were summed over a $2 \mathrm{~h}$ period following drug injection. $C, D$, The time course of limb and axial AIM during the $2 \mathrm{~h}$ period after L-DOPA at week 5 with chronic L-DOPA treatment. AAV-DT-A significantly reduced the overall limb and axial dyskinesia $(\boldsymbol{A}, \boldsymbol{B})$. L-DOPA did not induce dyskinesia in week 5 in mice with AAV-DT-A $(\boldsymbol{C}, \boldsymbol{D})$. The dyskinesia data represent the median ( $n=6$ mice for AAV-DT-A; $n=11-12$ mice for AAV-EYFP). $\boldsymbol{A}-\boldsymbol{D}$, The limb and axial dyskinesia between AAVEYFP and AAV-DT-A groups were overall statistically significant by Friedmans test ( $p<0.05$ ). *Significant difference versus baseline of the group after Wilcoxon post hoc test with Bonferroni adjustment ( $p<0.00278$ ). Motor performance was evaluated in lesioned mice using the forepaw adjusted stepping test before, and then 9-12 weeks following injection of AAV-EYFP (C) or AAV-DT-A (D). Postviral transduction, mice were tested before (BL) and $1 \mathrm{~h}$ after (Post) administration of vehicle $(12.5 \mathrm{mg} / \mathrm{kg}$ benserazide) or L-DOPA (3 mg/ $\mathrm{kg}$ ). The stepping data represent the mean + SEM ( $n=6$ mice for AAV-DT-A; $n=11-12$ mice for AAV-EYFP). $\boldsymbol{E}, \boldsymbol{F}$, ${ }^{*} p<0.05$ versus baseline before L-DOPA challenge, $\# p<0.05$ versus corresponding left paw steps, analyzed with two-way ANOVA followed by Tukey post hoc test based on the significant interaction between sides (left vs right) $\times$ time (BL vs Post) in vehicle or chronic L-DOPA-treated groups.

injection of AAV-DT-A or AAV-EYFP significantly altered baseline forelimb adjusting steps from previrus test performance. Vehicle treatment alone did not restore motor performance. However, L-DOPA improved stepping in the contralateral (right) forepaw of both virus-injected groups compared with vehicle treatment. Thus, ChI ablation does not affect lesion-induced stepping performance nor interfere with L-DOPA-induced improvement in akinesia.

\section{Discussion}

The mechanisms underlying the induction, maintenance, and expression of LID are complex and not fully understood. Our study is the first to demonstrate a functional consequence of the selective loss of striatal ChIs in reducing LID. Viral mediated DT-A induced specific and extensive (93\%) ChI depletion in lesioned striatum of hemiparkinsonian mice without significant damage of medium spiny neurons or other neurons as demonstrated by DARPP-32 and NeuN immunostaining, respectively. The observation that L-DOPA fully restored the stepping deficit in striatal ChI-depleted parkinsonian mice also argues that the attenuated LID is not due to a decreased response to L-DOPA and further indicates the involvement of different neural circuitries underlying LID and akinesia.

In addition to the possible involvement of cholinergic muscarinic receptors in LID (Ding et al., 2011), nicotinic acetylcholine receptor agonists have also been shown to reduce LID in partially DA denervated animals (Bordia et al., 2010; Quik et al., 2013), which is believed to occur through activation of presynaptic nicotinic receptors on DA terminals to promote DA release (Huang et al., 2011; Quik et al., 2013; Zhang et al., 2013; which may not be as significant in our model with near complete denervation), and release of glutamate from afferents from cortex and thalamus (Ding et al., 2008; Parikh et al., 2010). The importance of nondopaminergic transmitter systems that interact with dopaminergic projection in PD is apparent, and therefore pharmacologic agents directed toward serotonin, glutamate, adenosine, and cannabinoids are being investigated for potential anti-parkinsonian and anti-dyskinetic action (for review, see Pisani et al., 2007; Buck and Ferger, 2010; Oldenburg and Ding, 2011; Kalia et al., 2013). Relevant to the present study, investigations have shown that drugs targeting the cholinergic system may be beneficial for treating PD motor dysfunction. The striatum has the highest level of acetylcholine in brain, and although ChIs are few in number, they have widespread axonal arborizations which can modulate striatal activity via muscarinic and nicotinic receptors and subsequently influence behavior (Calabresi et al., 2000). DA and ACh are proposed to have opposing function such that there is a relative increase in striatal cholinergic activity in the face of a deficit in DA as occurs in PD (DeBoer et al., 1993; Pisani et al., 2007). Hypercholinergic neurotransmission has been implicated in PD motor symptoms because nonselective anticholinergic agents, such as benztropine and trihexyphenidyl, have been used clinically to alleviate tremor (Lees, 2005). Of note is our observation that elimination of striatal ChIs itself did not significantly alter akinesia measured by the stepping motor performance deficit produced by dopamine denervation. In contrast, reducing striatal ACh release by intrastriatal injection of botulinum neurotoxin-A has been shown to moderately improve contralateral forelimb use in hemiparkinsonian rats (Antipova et al., 2013).

The clinical evidence for the role of anticholinergic agents on dyskinesia is scanty and controversial, some noting reduction (Pourcher et al., 1989) and others noting worsening (BirketSmith, 1975) of dyskinesia. Recent reemergence of interest in defining precise roles of striatal cholinergic neurons in basal ganglia function include the efficacy of muscarinic antagonist, dicyclomine in reducing previously established LID in PD mouse models (Ding et al., 2011) and effect of nicotinic receptor inhibition on LID in hemiparkinsonian rats (Bordia et al., 2010). The present data along with our previous findings underscore the important role of enhanced striatal cholinergic activity in the induction and expression of LID. Cholinergic signaling may be a 
key target for the development of potential therapies to restore normal striatal ACh functional balance to prevent the onset of LID or delay its progression and severity.

\section{References}

Ahlskog JE, Muenter MD (2001) Frequency of levodopa-related dyskinesias and motor fluctuations as estimated from the cumulative literature. Mov Disord 16:448-458. CrossRef Medline

Andersson M, Hilbertson A, Cenci MA (1999) Striatal fosB expression is causally linked with L-DOPA-induced abnormal involuntary movements and the associated upregulation of striatal prodynorphin mRNA in a rat model of Parkinson's disease. Neurobiol Dis 6:461-474. CrossRef Medline

Andersson M, Konradi C, Cenci MA (2001) cAMP response elementbinding protein is required for dopamine-dependent gene expression in the intact but not the dopamine-denervated striatum. J Neurosci 21: 9930-9943. Medline

Antipova V, Hawlitschka A, Mix E, Schmitt O, Dräger D, Benecke R, Wree A (2013) Behavioral and structural effects of unilateral intrastriatal injections of botulinum neurotoxin a in the rat model of Parkinson's disease. J Neurosci Res 91:838-847. CrossRef Medline

Birket-Smith E (1975) Abnormal involuntary movements in relation to anticholinergics and levodopa therapy. Acta Neurol Scand 52:158-160. CrossRef Medline

Bordia T, Campos C, McIntosh JM, Quik M (2010) Nicotinic receptormediated reduction in L-DOPA-induced dyskinesias may occur via desensitization. J Pharmacol Exp Ther 333:929-938. CrossRef Medline

Buck K, Ferger B (2010) L-DOPA-induced dyskinesia in Parkinson's disease: a drug discovery perspective. Drug Discov Today 15:867-875. CrossRef Medline

Calabresi P, Centonze D, Gubellini P, Pisani A, Bernardi G (2000) Acetylcholine-mediated modulation of striatal function. Trends Neurosci 23:120-126. CrossRef Medline

Chang JW, Wachtel SR, Young D, Kang UJ (1999) Biochemical and anatomical characterization of forepaw adjusting steps in rat models of Parkinson's disease: studies on medial forebrain bundle and striatal lesions. Neuroscience 88:617-628. CrossRef Medline

Darmopil S, Martín AB, De Diego IR, Ares S, Moratalla R (2009) Genetic inactivation of dopamine D1 but not D2 receptors inhibits L-DOPAinduced dyskinesia and histone activation. Biol Psychiatry 66:603-613. CrossRef Medline

DeBoer P, Abercrombie ED, Heeringa M, Westerink BH (1993) Differential effect of systemic administration of bromocriptine and L-dopa on the release of acetylcholine from striatum of intact and 6-OHDA-treated rats. Brain Res 608:198-203. CrossRef Medline

Ding J, Peterson JD, Surmeier DJ (2008) Corticostriatal and thalamostriatal synapses have distinctive properties. J Neurosci 28:6483-6492. CrossRef Medline

Ding Y, Restrepo J, Won L, Hwang DY, Kim KS, Kang UJ (2007) Chronic 3,4-dihydroxyphenylalanine treatment induces dyskinesia in aphakia mice, a novel genetic model of Parkinson's disease. Neurobiol Dis 27:1123. CrossRef Medline

Ding Y, Won L, Britt JP, Lim SA, McGehee DS, Kang UJ (2011) Enhanced striatal cholinergic neuronal activity mediates L-DOPA-induced dyskinesia in parkinsonian mice. Proc Natl Acad Sci U S A 108:840-845. CrossRef Medline

Fahn S, Oakes D, Shoulson I, Kieburtz K, Rudolph A, Lang A, Olanow CW, Tanner C, Marek K (2004) Levodopa and the progression of Parkinson's disease. N Engl J Med 351:2498-2508. CrossRef Medline

Huang LZ, Campos C, Ly J, Ivy Carroll F, Quik M (2011) Nicotinic receptor agonists decrease L-dopa-induced dyskinesias most effectively in partially lesioned parkinsonian rats. Neuropharmacology 60:861-868. CrossRef Medline

Huot P, Johnston TH, Koprich JB, Fox SH, Brotchie JM (2013) The phar- macology of L-DOPA-induced dyskinesia in Parkinson's disease. Pharmacol Rev 65:171-222. CrossRef Medline

Jackson D, Abercrombie ED, Zigmond MJ (1993) Impact of L-dopa on striatal acetylcholine release: effects of 6-hydroxydopamine. J Pharmacol Exp Ther 267:912-918. Medline

Kalia LV, Brotchie JM, Fox SH (2013) Novel nondopaminergic targets for motor features of Parkinson's disease: review of recent trials. Mov Disord 28:131-144. CrossRef Medline

Lees A (2005) Alternatives to levodopa in the initial treatment of early Parkinson's disease. Drugs Aging 22:731-740. CrossRef Medline

Lundblad M, Picconi B, Lindgren H, Cenci MA (2004) A model of L-DOPAinduced dyskinesia in 6-hydroxydopamine lesioned mice: relation to motor and cellular parameters of nigrostriatal function. Neurobiol Dis 16: 110-123. CrossRef Medline

Malmlöf T, Rylander D, Alken RG, Schneider F, Svensson TH, Cenci MA Schilström B (2010) Deuterium substitutions in the L-DOPA molecule improve its anti-akinetic potency without increasing dyskinesias. Exp Neurol 225:408-415. CrossRef Medline

Maurice N, Mercer J, Chan CS, Hernandez-Lopez S, Held J, Tkatch T, Surmeier DJ (2004) $\mathrm{D}_{2}$ dopamine receptor-mediated modulation of voltage-dependent $\mathrm{Na}+$ channels reduces autonomous activity in striatal cholinergic interneurons. J Neurosci 24:10289-10301. CrossRef Medline

Oldenburg IA, Ding JB (2011) Cholinergic modulation of synaptic integration and dendritic excitability in the striatum. Curr Opin Neurobiol 21: 425-432. CrossRef Medline

Parikh V, Ji J, Decker MW, Sarter M (2010) Prefrontal beta2 subunitcontaining and alpha7 nicotinic acetylcholine receptors differentially control glutamatergic and cholinergic signaling. J Neurosci 30:35183530. CrossRef Medline

Paxinos G, Franklin KBJ (1997) The mouse brain in stereotaxic coordinates. San Diego: Elsevier.

Picconi B, Centonze D, Håkansson K, Bernardi G, Greengard P, Fisone G, Cenci MA, Calabresi P (2003) Loss of bidirectional striatal synaptic plasticity in L-DOPA-induced dyskinesia. Nat Neurosci 6:501-506. CrossRef Medline

Pisani A, Bernardi G, Ding J, Surmeier DJ (2007) Re-emergence of striatal cholinergic interneurons in movement disorders. Trends Neurosci 30: 545-553. CrossRef Medline

Pourcher E, Bonnet AM, Kefalos J, Dubois B, Agid Y (1989) Effects of etybenzatropine and diazepam on levodopa-induced diphasic dyskinesias in Parkinson's disease. Mov Disord 4:195-201. CrossRef Medline

Putterman DB, Munhall AC, Kozell LB, Belknap JK, Johnson SW (2007) Evaluation of levodopa dose and magnitude of dopamine depletion as risk factors for levodopa-induced dyskinesia in a rat model of Parkinson's disease. J Pharmacol Exp Ther 323:277-284. CrossRef Medline

Quik M, Campos C, Grady SR (2013) Multiple CNS nicotinic receptors mediate L-DOPA-induced dyskinesias: studies with parkinsonian nicotinic receptor knockout mice. Biochem Pharmacol 86:1153-1162. CrossRef Medline

Traka M, Arasi K, Avila RL, Podojil JR, Christakos A, Miller SD, Soliven B, Popko B (2010) A genetic mouse model of adult-onset, pervasive central nervous system demyelination with robust remyelination. Brain 133: 3017-3029. CrossRef Medline

Winkler C, Kirik D, Björklund A, Cenci MA (2002) L-DOPA-induced dyskinesia in the intrastriatal 6-hydroxydopamine model of parkinson's disease: relation to motor and cellular parameters of nigrostriatal function. Neurobiol Dis 10:165-186. CrossRef Medline

Witten IB, Lin SC, Brodsky M, Prakash R, Diester I, Anikeeva P, Gradinaru V, Ramakrishnan C, Deisseroth K (2010) Cholinergic interneurons control local circuit activity and cocaine conditioning. Science 330:16771681. CrossRef Medline

Zhang Y, Meredith GE, Mendoza-Elias N, Rademacher DJ, Tseng KY, SteeceCollier K (2013) Aberrant restoration of spines and their synapses in L-DOPA-induced dyskinesia: involvement of corticostriatal but not thalamostriatal synapses. J Neurosci 33:11655-11667. CrossRef Medline 